\title{
Correction to: Recording WAE Unmarked Graves in a Remote Aboriginal Community: The Challenge of Cultural Heritage Driving Sustainable Development
}

Jordan Ralph, College of Humanities, Arts and Social Sciences, Flinders University, Adelaide, Australia

E-mail: jordan.ralph@flinders.edu.au

Claire Smith, College of Humanities, Arts and Social Sciences, Flinders University, Adelaide, Australia

Gary Jackson, College of Humanities, Arts and Social Sciences, Flinders University, Adelaide, Australia

Isaac Brandon Pamkal, College of Humanities, Arts and Social Sciences, Flinders University, Adelaide, Australia; Jawoyn Association Aboriginal Corporation, Katherine, Australia

Jasmine Willika, College of Humanities, Arts and Social Sciences, Flinders University, Adelaide, Australia; Jawoyn Association Aboriginal Corporation, Katherine, Australia

Rusalka Rubio Perez, College of Humanities, Arts and Social Sciences, Flinders University, Adelaide, Australia

Nell Brown, Jawoyn Association Aboriginal Corporation, Katherine, Australia

Guy Rankin, Jawoyn Association Aboriginal Corporation, Katherine, Australia

Alok Kumar Kanungo, Indian Institute of Technology Gandhinagar Palaj, Gandhinagar, India

Nishaant Choksi, Indian Institute of Technology Gandhinagar Palaj, Gandhinagar, India

The Barunga Community, Jawoyn Association Aboriginal Corporation, Katherine, Australia

Published online: 2 June 2021 


\section{Correction to: Archaeologies: Journal of the World Archaeological Congress (2021) https://doi.org/10.1007/s11759-021-09417-y}

Due to proofing errors, in the Abstract section, the following text was shown incorrectly:

Beyond the archaeological results of this research, we found there is an opportunity to build sustainable development in this community that would see local people employed to locate and identify currently unidentified burials. Drawing on comparative cases from other countries such as India, this study addresses the challenge identified by UNESCO (United Nations Educational, Scientific and Cultural Organisation (UNESCO) (2015) introducing cultural heritage into the sustainable development agenda. Retrieved February 19, 2020, from http://www.unesco.org/new/en/ culture/themes/culture-and-development/hangzhou-congress/introducingcultural-heritage-into-the-sustainable-development-agenda/), to identify the concrete actions needed to integrate cultural heritage conservation and promotion into the sustainable development debate.

The text should have read as follows, including (in the digital version) a hot-link to the appropriate page on the UNESCO website:

Beyond the archaeological results of this research, we found there is an opportunity to build sustainable development in this community that would see local people employed to locate and identify currently unidentified burials. Drawing on comparative cases from other countries such as India, this study addresses the challenge identified by UNESCO (United Nations Educational, Scientific and Cultural Organisation (UNESCO) (2015), 'Introducing Cultural Heritage into the Sustainable Development Agenda'), of identifying the concrete actions needed to integrate cultural heritage conservation and promotion into the sustainable development debate.

This has been corrected by publishing this correction article.

Publisher's Note Springer Nature remains neutral with regard to jurisdictional claims in published maps and institutional affiliations. 